\title{
Meta-analysis in periprosthetic joint infection: a global bibliometric analysis
}

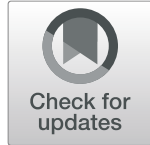

Cheng Li ${ }^{1} \mathbb{D}$, Christina Ojeda-Thies ${ }^{2}$, Chi $\mathrm{Xu}^{3}$ and Andrej Trampuz ${ }^{1 *}$

\begin{abstract}
Background: Periprosthetic joint infection (PJI) is the most serious complication of joint replacement surgery. Further comorbidities include bedsore, deep vein thrombosis, reinfection, or even death. An increasing number of researchers are focusing on this challenging complication. The aim of the present study was to estimate global PJ research based on bibliometrics from meta-analysis studies.

Methods: A database search was performed in PubMed, Scopus, and Web of Science. Relevant studies were assessed using the bibliometric analysis.

Results: A total of 117 articles were included. The most relevant literature on PJl was found on Scopus. China made the highest contributions to global research, followed by the USA and the UK. The institution with the most contributions was the University of Bristol. The journal with the highest number of publications was The Journal of Arthroplasty, whereas the Journal of Clinical Medicine had the shortest acceptance time. Furthermore, the top three frequently used databases were Embase, MEDLINE, and Cochrane. The most frequent number of authors in metaanalysis studies was four. Most studies focused on the periprosthetic hip and knee. The alpha-defensin diagnostic test, preventive measures on antibiotics use, and risk factors of intra-articular steroid injections were the most popular topic in recent years.

Conclusion: Based on the results of the present study, we found that there was no single database that covered all relevant articles; the optimal method for bibliometric analysis is a combination of databases. The most popular research topics on PJl focused on alpha-defensin, antibiotic use, risk factors of intra-articular steroid injections, and the location of prosthetic hip and knee infection.
\end{abstract}

Keywords: Bibliometrics, Arthroplasty, Surgical site infections, Periprosthetic joint infection, Meta-analysis, Research

\section{Introduction}

Periprosthetic joint infection (PJI) is a serious and challenging complication after joint replacement. Due to the lack of consensus on the management of PJI, physicians often face uncertainty. However, errors in diagnosis and treatment result in increased healthcare costs, reinfection, or mortality [1]. Publications play an essential role in guiding and improving disciplinary development.

\footnotetext{
* Correspondence: andrej.trampuz@charite.de

${ }^{1}$ Charité-Universitätsmedizin Berlin, corporate member of Freie Universität Berlin, Humboldt-Universität zu Berlin, and Berlin Institute of Health, Center for Musculoskeletal Surgery (CMSC), Charitéplatz 1, D-10117 Berlin, Germany Full list of author information is available at the end of the article
}

Bibliometric analysis is a widely used tool that uses mathematical and statistical methods to assess research trends and growth. Another commonly used tool is meta-analysis, a statistical method of collecting and analyzing results from multiple studies to find or prove the viewpoint or relationship between variables. These two methods have been applied extensively in orthopedic research [2-6]; however, there were few publications on the use of meta-analysis in bibliometric studies $[7,8]$. To date, no such studies have been performed on orthopedic research. 
The choice of database and the search strategy used are a crucial step in bibliometric studies and metaanalysis. Due to differences in exporting information between different databases, most bibliometric studies use a single database for statistics and data analysis $[9,10]$. Such differences regarding PJI research remained unknown. Accordingly, the present study performed a bibliometric analysis to determine the following: (1) the most suitable database (PubMed, Scopus, Web of Science) for bibliometric analysis [11]; (2) global research characteristics of PJI through the analysis of meta-analysis publications; (3) countries with the most research on the meta-analysis of PJI; (4) the diagnostic method with the highest sensitivity preoperatively, intraoperatively, and before reimplantation based on meta-analysis results; (5) the effective prevention measurement or risk factor on the meta-analysis of PJI; and (6) conclusions supported by the current meta-analysis.

\section{Materials and methods}

Data sources and searches

We systematically searched PubMed, Scopus, and Web of Science from inception to December 2019. The search algorithm used was the following medical subject headings (MeSH) or keywords: "arthroplasty", "joint prosthesis", "joint replacement", "periprosthetic joint", "prosthetic joint", "infection", "infectious", "infected", "meta analysis", and "meta-analysis". As this study was performed using global research, there were no language restrictions.

\section{Data collection}

Data were extracted independently by two reviewers (LC and COT). Discrepancies were adjudicated by the third author (XC). Information on all eligible publications including the title, author, year of publication, country, institution, journal, keywords, citations, state of the manuscript, language, number of studies, impact factor, software, database, search algorithm, and subject information were collected. The number of citations was based on the final result, in the case that no single database covered all citation information. Subsequently, citations were collected from Google scholar. Finally, two authors (LC and COT) manually screened and analyzed the publication information in Microsoft Excel (Microsoft, Redmond, Washington, USA, 2010) and EndNote X7 (Thomson Reuters, New York, NY, USA, 2013).

\section{Results}

\section{Database results}

Results from the search strategy demonstrated that the database with the most publications was Scopus (570), followed by Web of Science (341), and PubMed (243). The greatest number of identical articles was through the combined database of Web of Science and Scopus (Fig. 1). Finally, a total of 117 related articles were included. Of these, the database with most publications on the meta-analysis of PJI was Scopus, followed by Web of Science and PubMed. Web of Science and PubMed had most missed articles compared with other databases (Figs. 2 and 3).

\section{Characteristics of meta-analysis of PJI research General data}

Among the 117 meta-analysis articles, the earliest publications were from 2007. The greatest number of articles were published in 2018 (24), followed by 2017 and 2019 (21 each). The trend line indicates an annual increase in the number of articles (Fig. 4). One hundred and fourteen articles were in English, and three other articles were each published in Chinese, German, and Persian. In all meta-analyses, the number of studies included ranged from 4 to 203, with the highest number $12(n=$ 11 publications), followed by eight (9) as well as six and eleven studies (8 each).

\section{Countries}

Nineteen countries published meta-analyses on PJI. Of these, China was the most productive country, with all publications stemming from 15 cities/provinces. The highest number of articles originated from Shanghai, followed by Beijing (Fig. 5). The country with the second highest number of publications on PJI was the US, followed by the UK (Table 1).

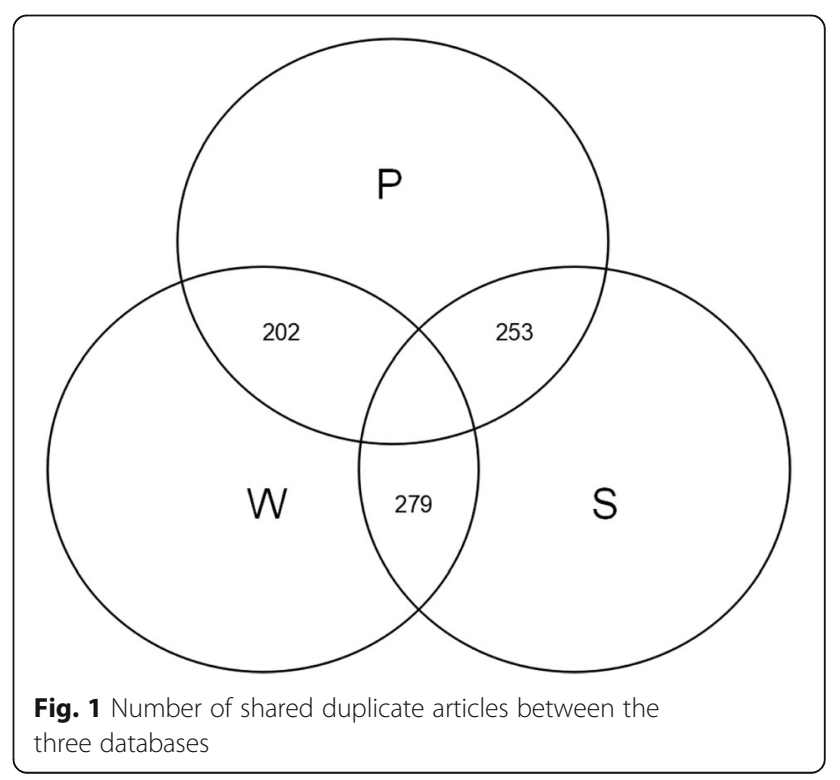




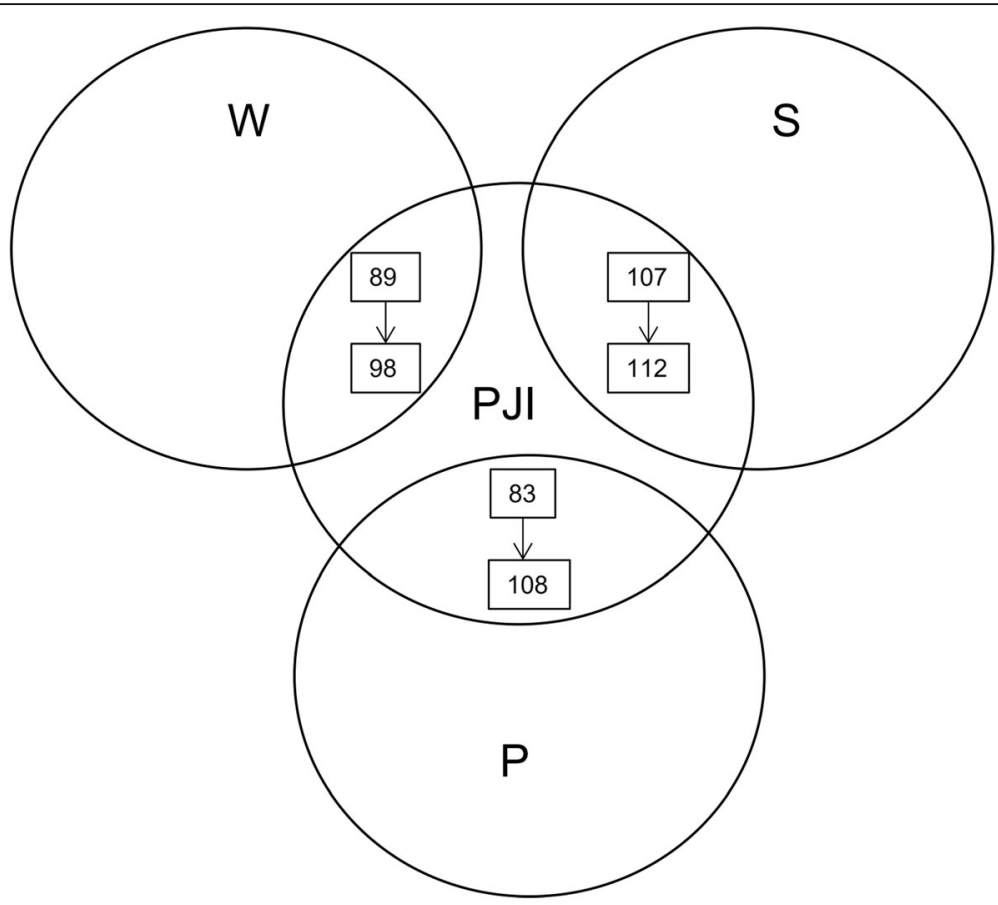

Fig. 2 Number of shared PJI research articles of meta-analysis between the three databases (with or without search algorithms)

\section{Institutions}

A total of 76 institutions made contributions to this field. The institution with the greatest number of publications was the University of Bristol with 11 papers, followed by Shanghai Sixth People's Hospital (8). The Rothman Institute and General Hospital of the Chinese

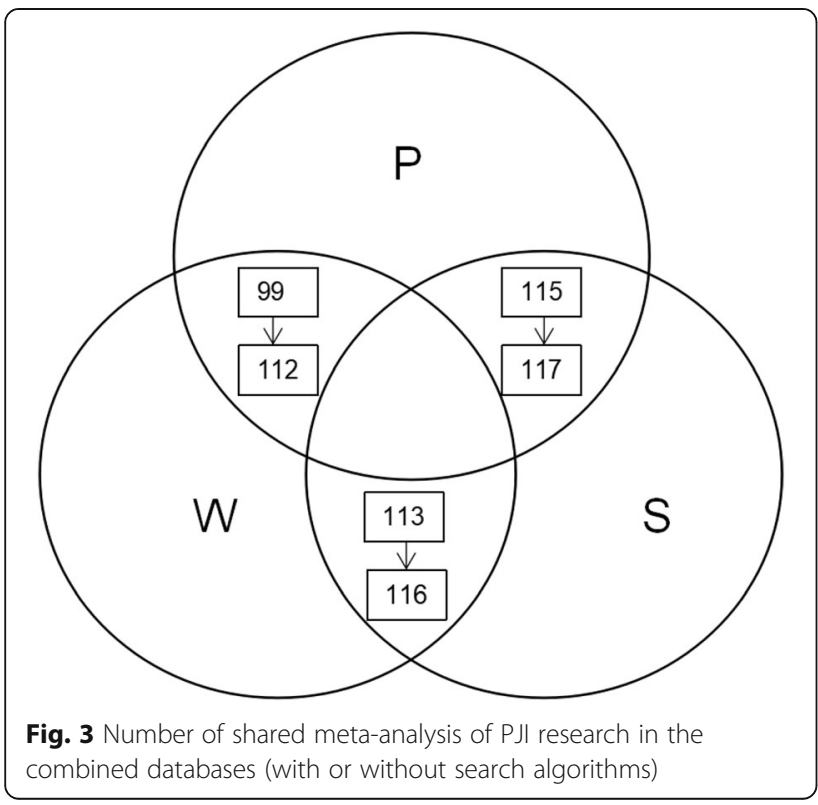

People's Liberation Army were third, with each publishing five research articles. Fourteen institutions published more than one paper, with $50 \%$ originating from China (Table 2).

\section{Authors}

The number of authors of a single article ranged from 2 to 37 . The largest number of collaborating authors was four (27), followed by six (25) and 5 authors (20; Table 3). The author with most first authorships was Setor K. Kunutsor (10), followed by Xinhua $\mathrm{Qu}$ (3). Ten first authors wrote more than one meta-analysis, with $50 \%$ published by research institutes in China (Table 4).

\section{Journals}

Meta-analysis studies were published in 54 different journals. The journal with most publications was the Journal of Arthroplasty, with 15 publications. The Journal of Bone and Joint Surgery ranked second with eight publications, whereas PLoS ONE was third with seven. Nineteen journals had more than one publication (Table 5). In 2019, an impact factor was available for 42 journals. The list of top 10 journals with the highest impact factors is shown in Table 6 .

From all publications, the date of receipt was available for 89 papers, whereas the date of acceptance for 

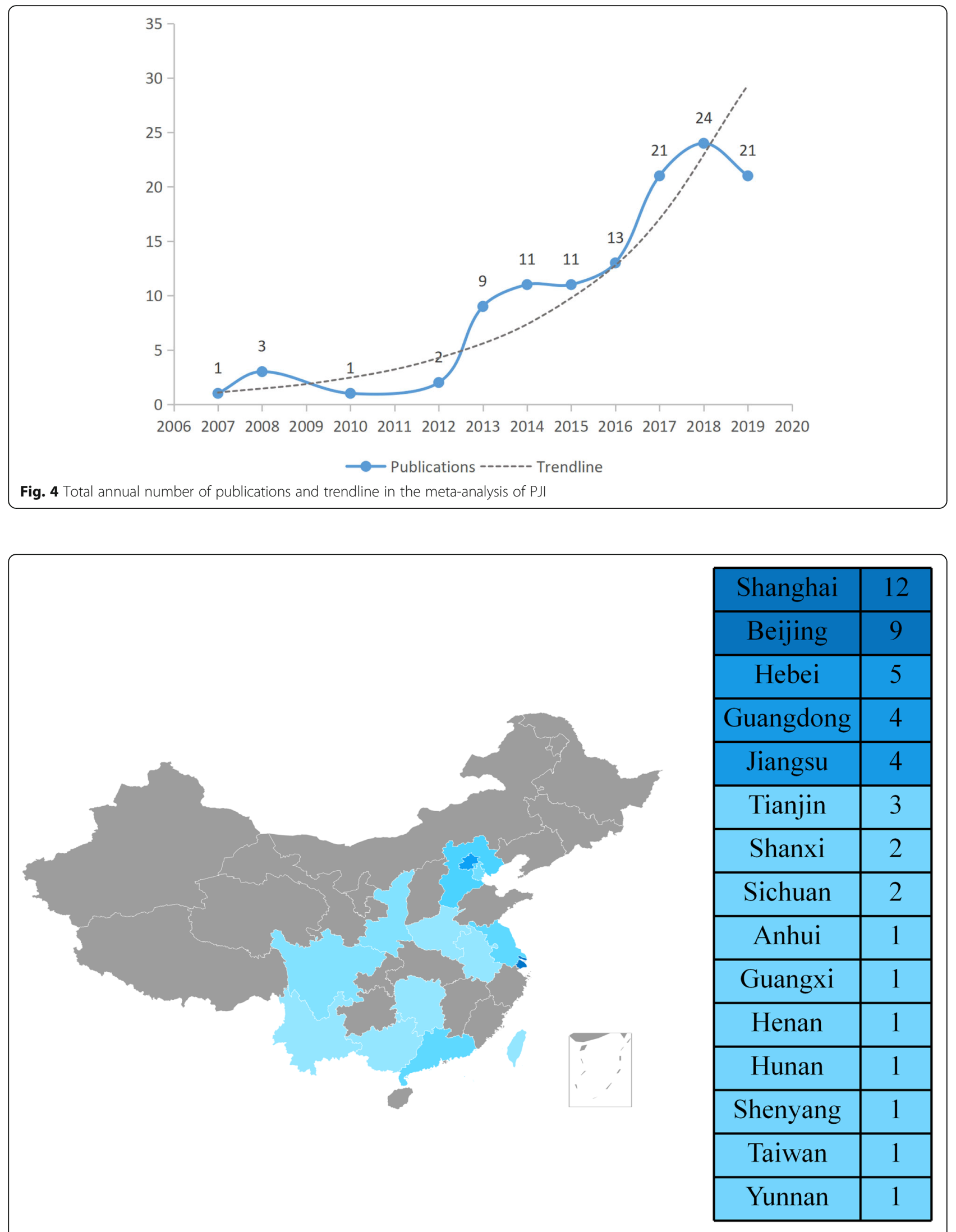

Fig. 5 Map showing the distribution of meta-analysis studies on PJl from China 
Table 1 Global distribution of meta-analysis studies on PJI

\begin{tabular}{ll}
\hline Country & Number of articles \\
\hline China & 48 \\
USA & 20 \\
UK & 18 \\
Germany & 4 \\
South Korea & 4 \\
Italy & 3 \\
Netherlands & 3 \\
Canada & 3 \\
Australia & 2 \\
Colombia & 2 \\
Greece & 2 \\
Brazil & 1 \\
Denmark & 1 \\
Iran & 1 \\
Portugal & 1 \\
South Africa & 1 \\
Spain & 1 \\
Sweden & 1 \\
Switzerland & 1 \\
\hline
\end{tabular}

85 , and the date of publication for 72 . From the date of receipt to acceptance, information was available for 65 articles, with the average number of days until acceptance 95.69. Among these 65 articles, 11 journals had more than two publications, whereas four journals had an average acceptance time of fewer than
Table 3 Number of collaborating authors in meta-analysis studies on PJI

\begin{tabular}{ll}
\hline Number of authors & Total number \\
\hline 4 & 27 \\
6 & 25 \\
5 & 20 \\
3 & 15 \\
7 & 10 \\
8 & 6 \\
10 & 3 \\
2 & 2 \\
9 & 2 \\
13 & 2 \\
27 & 2 \\
11 & 1 \\
18 & 1 \\
37 & 1 \\
\hline
\end{tabular}

100 days. These are the Journal of Orthopaedic Surgery and Research (68 days), followed by the Journal of Hospital Infection (82 days), Journal of Clinical Microbiology (83 days), and Journal of Arthroplasty (86 days).

The average number of days from acceptance to publication was 56.52 (66 papers). From receipt to online publication, the average number of days was 157.48 (69). There were six articles accepted in less than 30 days after submission. The journal with the shortest acceptance time was the Journal of Clinical Medicine (16 days), followed by the Journal of

Table 2 Top 14 institutions and countries of meta-analysis studies on PJ

\begin{tabular}{lll}
\hline Name of institution & Publication & Country \\
\hline University of Bristol & 11 & UK \\
Shanghai Sixth People's Hospital & 8 & China \\
Rothman Institute & 5 & USA \\
General Hospital of Chinese People's Liberation Army & 5 & China \\
The Third Hospital of Hebei Medical University & 4 & China \\
Tianjin Hospital & 3 & China \\
Mayo Clinic Hospital & 3 & USA \\
Charité - Universitätsmedizin Berlin & 3 & Germany \\
West China Hospital & 2 & China \\
Medical Centre Alkmaar & 2 & Netherlands \\
McMaster University & 2 & Canada \\
Federico II University & 2 & Italy \\
Beijing Jishuitan Hospital & 2 & China \\
Beijing Friendship Hospital of Capital Medical University & 2 & China \\
\hline
\end{tabular}


Table 4 List of top 10 first authors with number of publications and institution of meta-analysis studies on PJI.

\begin{tabular}{lll}
\hline First author & Publications & Institution \\
\hline Setor K. Kunutsor & 10 & University of Bristol \\
Qu Xinhua & 3 & Shanghai Ninth People's Hospital \\
Giovanni Balato & 2 & Federico II University \\
Yong Seuk Lee & 2 & Rothman Institute \\
Li Cheng & 2 & Charité Universitätsmedizin Berlin \\
Steven J. Verberne & 2 & Medical Centre Alkmaar \\
Wang Chi & 2 & General Hospital of Chinese People's Liberation Army \\
Xu Chi & 2 & General Hospital of Chinese People's Liberation Army \\
Dan Xing & 2 & Tianjin Hospital \\
Xie Kai & 2 & Shanghai Ninth People's Hospital
\end{tabular}

Computational and Theoretical Nanoscience (18 days), Journal of Clinical Medicine (22 days), Journal of Arthroplasty (23 days), Journal of Orthopaedic Surgery and Research as well as Medical Science Monitor (27 days each).

\section{Most cited publications}

From Google Scholar, citation information was available for 103 meta-analyses. Forty-one articles were cited more than 20 times, with the highest number in 2014 (9), followed by 2013, 2016, and 2017 (7 each). The most cited article was published by AlBuhairan et al. [12] (264), followed by Parvizi et al. [13] (235; Table 7).

\section{Search algorithm and keywords}

One hundred and two meta-analyses were retrieved from the search strategy, which were exported to Microsoft Excel. All keywords or MeSH were combined. PJI-related keywords were 196, followed by diagnosis (179), prevention (82), risk factor (74), and outcome (60). All keywords are presented in Supplementary 1. From 71 publications, 389 keywords were exported. Periprosthetic joint infection (41) was the most commonly used keyword,

Table 5 Top 19 journals with number of publications and their corresponding impact factor of meta-analysis studies on PJI

\begin{tabular}{lll}
\hline Journal & Number of publications & Impact factor \\
\hline Journal of Arthroplasty & 15 & 3.524 \\
$\quad$ Journal of Bone and Joint Surgery-American Volume & 8 & 4.716 \\
PLoS ONE & 7 & 2.776 \\
Surgical Infections & 6 & 1.921 \\
International Orthopaedics & 5 & 2.384 \\
Bone and Joint Journal & 5 & 4.301 \\
Archives of Orthopaedic and Trauma Surgery & 3 & 1.973 \\
BMC Musculoskeletal Disorders & 3 & 2.002 \\
Clinical Orthopaedics and Related Research & 3 & 4.154 \\
International Journal of Clinical and Experimental Medicine & 3 & 0.181 \\
Journal of Clinical Microbiology & 3 & 4.959 \\
Journal of Hospital Infection & 3 & 3.704 \\
Journal of Orthopaedic Surgery and Research & 3 & 1.907 \\
Knee Surgery Sports Traumatology Arthroscopy & 3 & 3.149 \\
Medicine & 3 & 1.87 \\
Orthopedics & 3 & 1.608 \\
\hline
\end{tabular}


Table 6 List of top 10 highest impact factor journals with number of PJI publications in meta-analysis

\begin{tabular}{lll}
\hline Journal & Number of publications & Impact factor \\
\hline Radiology & 1 & 7.608 \\
European Journal of Nuclear Medicine and Molecular Imaging & 1 & 7.182 \\
European Journal of Epidemiology & 1 & 6.529 \\
Journal of Clinical Medicine & 2 & 5.688 \\
Journal of Antimicrobial Chemotherapy & 1 & 5.113 \\
Regional Anesthesia and Pain Medicine & 1 & 5.113 \\
Journal of Infection & 1 & 5.099 \\
Journal of Clinical Microbiology & 3 & 4.959 \\
Journal of Bone and Joint Surgery-American Volume & 8 & 4.716 \\
Antimicrobial Agents and Chemotherapy & 1 & 4.715
\end{tabular}

followed by meta-analysis (29) and total knee arthroplasty (20; Table 8).

\section{Database and software}

After combining all databases from 116 articles, there were a total of 52 databases. Embase was the most described database (101), followed by MEDLINE (80), and Cochrane (74; Table 9). Three databases were most frequently searched (40), followed by four (22), and five (16). The most combined database group was Cochrane Library + Embase + MEDLINE/PubMed (10), followed by Embase + MEDLINE (6), and Cochrane Library + Embase + MEDLINE + Web of Science (5).

For the meta-analysis, 13 softwares were exported from 106 articles. The most commonly used software was STATA (43), followed by REVMAN (25), and MetaDisc (21).

\section{Subject}

Location Information on the site of prosthetic joint infection from the included meta-analysis were found in 112 papers. The location with the highest number was the knee (93), closely pursued by the hip (90), shoulder (23), elbow (16), and ankle (3).

Diagnosis of PJI From 40 diagnosis-related metaanalyses, 72 tests were related to preoperative examination, followed by intraoperative methods (12), and test prior to reimplantation (14). Synovial fluid alphadefensin had highest pooled sensitivities in the list of preoperative examinations, pursued by serum IL-6 and bone scintigraphy. From all intraoperative examinations, tissue polymerase chain reaction (PCR) was the most sensitive method, followed by sonicate fluid into blood culture bottles (BCB) and PCR. Tissue culture was the most sensitive method before reimplantation, followed by the percentage of polymorphonucleocytes in synovial fluid (PMN\%), and synovial fluid culture (Table 10). The most frequent diagnostic method used was synovial fluid (16), followed by imaging (10), and periprosthetic tissue (7; Fig. 6).

Risk factor and prevention Twenty-three articles described 64 possible risk factors. The location of the risk factor was outlined in 20 studies, with the majority in the hip and knee (Table 11). Nine preventive measures were described in 17 articles, with all focusing on the hip and knee (Table 12).

Comparative analysis There were 26 comparative analytic studies from all meta-analyses, with most related to the hip and knee (11), followed by the hip as well as the hip and knee (7 each). There was no statistical difference found in 13 comparison studies (Table 13).

\section{Discussion}

This bibliometric study presents 117 meta-analysis results from three databases (PubMed, Scopus, and Web of Science), with the greatest number of relevant papers in Scopus. Furthermore, we compared all databases with or without a search strategy, with PubMed demonstrating the greatest difference among the three databases. When combined with other databases, the missing information from the search strategy could be supplemented. All results could not be found with any of the databases, with or without a search strategy, whereas the combination of PubMed and Scopus enclosed all results without a search strategy. In addition, all available information from the database and search algorithm were collected and combined. Three to five database groups were found to comprise most options for meta-analysis. Embase, MEDLINE, and Cochrane were the top three most commonly used databases and were also mostly used for meta- 
Table 7 The 50 most cited meta-analysis studies on PJI ranked by citation.

Rank Title Times

$1 \quad$ Antibiotic prophylaxis for wound infections in total joint arthroplasty: a systematic review

cited

2 Efficacy of antibiotic-impregnated cement in total hip replacement: a meta-analysis meta-analysis

$5 \quad$ FDG-PET for diagnosing prosthetic joint infection: systematic review and metaanalysis

Patient-related risk factors for periprosthetic joint infection after total joint arthroplasty: a systematic review and meta-analysis

$7 \quad$ Chronic infections in hip arthroplasties: comparing risk of reinfection following one-stage and two-stage revision: a systematic review and meta-analysis

8 Risk factors for periprosthetic joint infection after total joint arthroplasty: a systematic review and meta-analysis

9 The alpha-defensin immunoassay and leukocyte esterase colorimetric strip test for the diagnosis of periprosthetic infection a systematic review and meta-analysis

10 A systematic review and meta-analysis of antibiotic-impregnated bone cement use in primary total hip or knee arthroplasty

11 Risk factors for deep infection after total knee arthroplasty: a meta-analysis

12 Infection after primary total hip arthroplasty

13 Re-infection outcomes following one- and two-stage surgical revision of infected knee prosthesis: a systematic review and metaanalysis

14 Prosthesis infection: diagnosis after total joint arthroplasty with antigranulocyte scintigraphy with99mTc-labeled monoclonal antibodies - a meta-analysis

15 Allogeneic blood transfusion is a significant risk factor for surgical-site infection following total hip and knee arthroplasty: a metaanalysis

16 Inflammatory blood laboratory levels as markers of prosthetic joint infection: a systematic review and meta-analysis

74

Meta-analysis of sonication fluid samples from prosthetic components for diagnosis of infection after total joint arthroplasty

18 Re-infection outcomes following one- and two-stage surgical revision of infected hip prosthesis: a systematic review and metaanalysis

19 Use of static or articulating spacers for infection following total knee arthroplasty

20 PCR-based diagnosis of prosthetic joint infection

21 Preoperative aspiration culture for preoperative diagnosis of infection in total hip or knee arthroplasty

Synovial fluid biomarkers for the diagnosis of periprosthetic joint infection: a systematic review and meta-analysis 47

Evaluation of white cell count and differential in synovial fluid for diagnosing infections after total hip or knee arthroplasty 35

Prosthesis infection: diagnosis after total joint arthroplasty with three-phase bone scintigraphy 35

Diagnostic performance of FDG PET or PET/CT in prosthetic infection after arthroplasty: a meta-analysis 34

Procalcitonin and a-defensin for diagnosis of periprosthetic joint infections 34

The accuracy of imaging techniques in the assessment of periprosthetic hip infection: a systematic review and meta-analysis 32

Control strategies to prevent total hip replacement-related infections: a systematic review and mixed treatment comparison 30

29 Outcomes following debridement, antibiotics and implant retention in the management of periprosthetic infections of the hip: a 30 review of cohort studies

30 Total joint arthroplasty following intra-articular steroid injection: a literature review

31 Do intra-articular steroid injections increase infection rates in subsequent arthroplasty? A systematic review and meta-analysis of 29 comparative studies

32 Postoperative antibiotic prophylaxis in total hip and knee arthroplasty: a systematic review and meta-analysis of randomized controlled trials

33 What is the accuracy of nuclear imaging in the assessment of periprosthetic knee infection? A meta-analysis

34 Does previous intra-articular steroid injection increase the risk of joint infection following total hip arthroplasty or total knee arthro- 27 plasty? A meta-analysis

35 Systematic review and meta-analysis of randomized controlled trials of antibiotics and antiseptics for preventing infection in people 25 receiving primary total hip and knee prostheses

36 Diagnostic accuracy of C-reactive protein for periprosthetic joint infection: a meta-analysis 
Table 7 The 50 most cited meta-analysis studies on PJI ranked by citation. (Continued)

\begin{tabular}{|c|c|c|}
\hline Rank & Title & $\begin{array}{l}\text { Times } \\
\text { cited }\end{array}$ \\
\hline 37 & $\begin{array}{l}\text { Use of anti-granulocyte scintigraphy with } 99 \mathrm{mTc} \text {-labeled monoclonal antibodies for the diagnosis of periprosthetic infection in pa- } \\
\text { tients after total joint arthroplasty: a diagnostic meta-analysis }\end{array}$ & 24 \\
\hline 38 & Serum and synovial fluid interleukin-6 for the diagnosis of periprosthetic joint infection & 23 \\
\hline 39 & The application of sonication in diagnosis of periprosthetic joint infection & 22 \\
\hline 40 & $\begin{array}{l}\text { The impact of neuraxial versus general anesthesia on the incidence of postoperative surgical site infections following knee or hip } \\
\text { arthroplasty a meta-analysis }\end{array}$ & 22 \\
\hline 41 & $\begin{array}{l}\text { Do 'Surgical Helmet Systems' or 'Body Exhaust Suits' affect contamination and deep infection rates in arthroplasty? A systematic } \\
\text { review }\end{array}$ & 21 \\
\hline
\end{tabular}

analysis. The available search algorithm exported from 102 publications provided a reference for scholars for a further literature search and study design.

Meta-analysis could offer a useful effective reference to support or refute controversial conclusions from multiple studies. The bibliometric analysis showed that the first meta-analysis appeared in 2007, with an increasing trend in the ensuing years. The growth number likely reflects the development of the subject with an academic dispute, and the International Consensus Meeting on PJI also indicated the presence of disparate opinions on the management of PJI [54]. The current study also presented China as having the greatest number of publications in meta-analyses. This may be attributed to the fact that Chinese physicians are placed under immense pressure to publish under the healthsystem reforms [55]. Furthermore, the Chinese Association of Orthopaedic Surgeons (CAOS) play close attention to infection after joint arthroplasty. CAOS, which comprises the Chinese prosthetic joint infection society, was established in 2018 and perform PJI research by multiple centers. In China, Beijing and Shanghai had the greatest number of publication of PJI meta-analysis than other cities and is most likely related to a larger number of research institution concentrated in both regions. Institutions from the UK had the largest number of publications, with the majority from the University of Bristol. Analysis of author information showed that at least two authors were required for meta-analysis, with the most frequent number of collaborators was four. In meta-analysis studies, Setor K. Kunutsor from the University of Bristol had the most publications as the first author.

In all meta-analysis papers, the Journal of Arthroplasty had the most number of relevant papers. With more than 20 citations, PLoS ONE had the greatest number of publications from the most cited publication list. The Journal of Clinical Medicine had the minimum time from receipt to acceptance. In addition, the bibliometric method report showed most articles to be received and accepted on Wednesday.

In the top 10 most popular keywords on PJI metaanalysis, two keywords were related to treatment and diagnosis, with two-stage exchange and alpha-defensin in the top 10. Three keywords were associated with the location of PJI, with the majority on the hip and

Table 8 List of top 10 keywords of PJl publications in meta-

\begin{tabular}{ll} 
analysis & \\
\hline Keywords & Occurrence $(\boldsymbol{n})$ \\
\hline Periprosthetic joint infection & 41 \\
Meta-analysis & 29 \\
Total knee arthroplasty & 20 \\
Arthroplasty & 18 \\
Infection & 17 \\
Total hip arthroplasty & 13 \\
Two stage & 10 \\
Alpha-defensin & 9 \\
Total joint arthroplasty & 9 \\
Knee & 9
\end{tabular}

Table 9 List of top 10 databases of PJI in meta-analysis

\begin{tabular}{ll}
\hline Database & Occurrence $(\boldsymbol{n})$ \\
\hline Embase & 101 \\
MEDLINE & 80 \\
Cochrane & 74 \\
PubMed & 57 \\
Web of Science & 36 \\
OVID & 14 \\
Scopus & 14 \\
Science Direct & 12 \\
Google Scholar & 9 \\
CNKI & 8 \\
\hline
\end{tabular}


Table 10 Diagnostic methods used for PJ detection ranked by the sensitivity (preoperative examination, intraoperative methods, and test before reimplantation)

\begin{tabular}{|c|c|c|c|c|c|}
\hline & Reference & Year & No. of studies & Sen $(95 \% \mathrm{Cl})$ & Spe $(95 \% \mathrm{Cl})$ \\
\hline \multicolumn{6}{|l|}{ Preoperative examination } \\
\hline Synovial fluid alpha-defensin immunoassay & [14] & 2016 & 6 & $1.00(0.82-1.00)$ & $0.96(0.89-0.99)$ \\
\hline Synovial fluid ELISA & [15] & 2018 & 4 & $0.98(0.94-1.00)$ & $0.97(0.95-0.99)$ \\
\hline Synovial fluid alpha-defensin immunoassay & [16] & 2019 & 7 & $0.98(0.94-0.99)$ & $0.96(0.94-0.98)$ \\
\hline Synovial fluid a-defensin & {$[17]$} & 2017 & 7 & $0.97(0.93-0.99)$ & $0.96(0.94-0.98)$ \\
\hline Serum IL-6 & [18] & 2010 & 3 & $0.97(0.93-0.99)$ & $0.91(0.87-0.94)$ \\
\hline Synovial fluid ELISA & [19] & 2018 & 4 & $0.97(0.91-0.99)$ & $0.97(0.94-0.98)$ \\
\hline Synovial fluid alpha-defensin immunoassay & [20] & 2018 & 4 & $0.96(0.90-0.98)$ & $0.96(0.93-0.97)$ \\
\hline Synovial fluid alpha-defensin & [21] & 2017 & 11 & $0.96(0.87-0.99)$ & $0.95(0.91-0.97)$ \\
\hline Synovial fluid alpha-defensin & [22] & 2016 & 6 & $0.96(0.85-0.99)$ & $0.95(0.89-0.98)$ \\
\hline Synovial fluid alpha-defensin immunoassay & [23] & 2018 & 7 & $0.95(0.87-0.98)$ & $0.97(0.94-0.98)$ \\
\hline Synovial fluid ELISA & [24] & 2018 & 4 & $0.95(0.91-0.98)$ & $0.97(0.95-0.98)$ \\
\hline Bone scintigraphy & [25] & 2017 & 6 & $0.93(0.85-0.98)$ & $0.56(0.47-0.64)$ \\
\hline Synovial fluid CRP & [26] & 2016 & 6 & $0.92(0.86-0.96)$ & $0.90(0.87-0.93)$ \\
\hline Synovial fluid ELISA & [27] & 2019 & 4 & $0.92(0.86-0.96)$ & $0.99(0.98-1.00)$ \\
\hline Synovial fluid LE & [28] & 2015 & 4 & $0.92(0.86-0.96)$ & $0.95(0.93-0.97)$ \\
\hline Synovial fluid PMN\% & [29] & 2018 & 10 & $0.91(0.87-0.93)$ & $0.86(0.81-0.90)$ \\
\hline Synovial fluid IL-6 & {$[30]$} & 2017 & 8 & $0.91(0.82-0.96)$ & $0.90(0.84-0.95)$ \\
\hline Synovial fluid WCC/PMN\% & [31] & 2014 & 9 & $0.91(0.82-0.95)$ & $0.89(0.81-0.94)$ \\
\hline Synovial fluid WBC & [29] & 2018 & 10 & $0.90(0.87-0.92)$ & $0.90(0.81-0.95)$ \\
\hline Synovial fluid PMN\% & [31] & 2014 & 14 & $0.90(0.84-0.93)$ & $0.88(0.83-0.92)$ \\
\hline AGS & {$[25]$} & 2017 & 5 & $0.90(0.78-0.96)$ & $0.95(0.88-0.98)$ \\
\hline Synovial fluid LE & {$[32]$} & 2018 & 8 & $0.90(0.76-0.96)$ & $0.97(0.95-0.98)$ \\
\hline Synovial fluid leukocyte count & {$[17]$} & 2017 & 12 & $0.89(0.86-0.91)$ & $0.86(0.80-0.90)$ \\
\hline Synovial fluid PMN\% & [17] & 2017 & 10 & $0.89(0.82-0.93)$ & $0.86(0.77-0.92)$ \\
\hline Serum CRP & [18] & 2010 & 23 & $0.88(0.86-0.90)$ & $0.74(0.71-0.76)$ \\
\hline Synovial fluid WCC & [31] & 2014 & 15 & $0.88(0.81-0.93)$ & $0.93(0.88-0.96)$ \\
\hline Leukocyte scintigraphy & [25] & 2017 & 6 & $0.88(0.81-0.93)$ & $0.77(0.69-0.85)$ \\
\hline Leukocyte scintigraphy & [33] & 2016 & 6 & $0.88(0.81-0.94)$ & $0.92(0.88-0.96)$ \\
\hline 18F-FDG PET or PET/CT & [34] & 2017 & 16 & $0.87(0.83-0.90)$ & $0.87(0.85-0.89)$ \\
\hline Serum CRP & [35] & 2017 & 11 & $0.87(0.84-0.90)$ & $0.79(0.77-0.80)$ \\
\hline Bone and leukocyte scintigraphy & [25] & 2017 & 4 & $0.87(0.71-0.96)$ & $0.82(0.72-0.90)$ \\
\hline Synovial fluid IL-8 & {$[17]$} & 2017 & 3 & $0.87(0.67-0.96)$ & $0.94(0.88-0.97)$ \\
\hline Serum ESR & {$[35]$} & 2017 & 12 & $0.86(0.83-0.89)$ & $0.72(0.70-0.74)$ \\
\hline FDG PET or PET/CT & {$[36]$} & 2013 & 14 & $0.86(0.82-0.90)$ & $0.86(0.83-0.89)$ \\
\hline Synovial fluid CRP & [19] & 2018 & 9 & $0.86(0.81-0.91)$ & $0.90(0.86-0.93)$ \\
\hline FDG PET & [33] & 2016 & 12 & $0.86(0.80-0.90)$ & $0.93(0.90-0.95)$ \\
\hline Synovial fluid lateral flow test & [27] & 2019 & 12 & $0.85(0.80-0.89)$ & $0.96(0.94-0.97)$ \\
\hline Synovial fluid CRP & {$[17]$} & 2017 & 10 & $0.85(0.78-0.90)$ & $0.88(0.78-0.94)$ \\
\hline Synovial fluid lateral flow test & [24] & 2018 & 6 & $0.85(0.74-0.92)$ & $0.90(0.91-0.98)$ \\
\hline Synovial fluid/serum CRP & {$[28]$} & 2015 & 15 & $0.845(0.82-0.87)$ & $0.795(0.78-0.81)$ \\
\hline Synovial fluid PCR & [37] & 2013 & 6 & $0.84(0.75-0.93)$ & $0.89(0.81-0.97)$ \\
\hline Synovial fluid lateral flow test & [16] & 2019 & 6 & $0.84(0.74-0.91)$ & $0.94(0.89-0.97)$ \\
\hline
\end{tabular}


Table 10 Diagnostic methods used for PJl detection ranked by the sensitivity (preoperative examination, intraoperative methods, and test before reimplantation) (Continued)

\begin{tabular}{|c|c|c|c|c|c|}
\hline & Reference & Year & No. of studies & $\operatorname{Sen}(95 \% \mathrm{Cl})$ & Spe $(95 \% \mathrm{Cl})$ \\
\hline AGS & [33] & 2016 & 5 & $0.84(0.70-0.93)$ & $0.75(0.66-0.82)$ \\
\hline AGS with monoclonal antibodies & [38] & 2007 & 13 & $0.83(0.75-0.89)$ & $0.80(0.75-0.84)$ \\
\hline Anti-granulocyte scintigraphy with $99 \mathrm{~m}$ Tc-labeled monoclonal antibodies & [39] & 2013 & 19 & $0.83(0.79-0.87)$ & $0.79(0.75-0.83)$ \\
\hline Synovial fluid/serum IL-6 & [40] & 2018 & 18 & $0.83(0.74-0.89)$ & $0.91(0.84-0.95)$ \\
\hline Three-phase bone scintigraphy & [41] & 2014 & 20 & $0.83(0.72-0.90)$ & $0.73(0.65-0.80)$ \\
\hline Synovial fluid/serum IL-6 & [28] & 2015 & 11 & $0.824(0.78-0.87)$ & $0.85(0.82-0.88)$ \\
\hline FDG-PET & [42] & 2008 & 11 & $0.82(0.68-0.91)$ & $0.87(0.80-0.91)$ \\
\hline Serum CRP & [43] & 2014 & 25 & $0.82(0.80-0.84)$ & $0.77(0.76-0.78)$ \\
\hline Synovial fluid IL-6 & [17] & 2017 & 5 & $0.81(0.70-0.89)$ & $0.94(0.88-0.97)$ \\
\hline Synovial fluid LE & [14] & 2016 & 5 & $0.81(0.49-0.95)$ & $0.97(0.82-0.99)$ \\
\hline Bone scintigraphy & [33] & 2016 & 8 & $0.80(0.72-0.86)$ & $0.69(0.64-0.73)$ \\
\hline Leukocyte and bone marrow scintigraphy & [25] & 2017 & 7 & $0.80(0.66-0.91)$ & $0.93(0.86-0.97)$ \\
\hline Synovial fluid Synovasure & [19] & 2018 & 6 & $0.80(0.65-0.89)$ & $0.89(0.76-0.96)$ \\
\hline Synovial fluid LE & [27] & 2019 & 12 & $0.79(0.75-0.82)$ & $0.96(0.95-0.97)$ \\
\hline Synovial fluid LE & [19] & 2018 & 12 & $0.79(0.67-0.87)$ & $0.92(0.87-0.92)$ \\
\hline Synovial fluid lateral flow test & [23] & 2018 & 3 & $0.77(0.64-0.87)$ & $0.91(0.83-0.96)$ \\
\hline Synovial fluid LE & [17] & 2017 & 5 & $0.77(0.63-0.87)$ & $0.95(0.86-0.98)$ \\
\hline Synovial fluid IL-6 & [19] & 2018 & 11 & $0.76(0.65-0.84)$ & $0.91(0.88-0.94)$ \\
\hline Serum ESR & [18] & 2010 & 25 & $0.75(0.72-0.77)$ & $0.70(0.68-0.72)$ \\
\hline Synovial fluid culture & [44] & 2013 & 34 & $0.72(0.65-0.78)$ & $0.95(0.93-0.97)$ \\
\hline Serum IL-6 & [30] & 2017 & 11 & $0.72(0.63-0.80)$ & $0.89(0.77-0.95)$ \\
\hline Synovial fluid lateral flow test & {$[20]$} & 2018 & 3 & $0.71(0.55-0.83)$ & $0.90(0.81-0.95)$ \\
\hline FDG-PET & [25] & 2017 & 5 & $0.70(0.56-0.81)$ & $0.84(0.76-0.90)$ \\
\hline Leukocyte and bone marrow scintigraphy & [33] & 2016 & 3 & $0.69(0.58-0.79)$ & $0.96(0.93-0.98)$ \\
\hline Synovial fluid culture & {$[17]$} & 2017 & 5 & $0.62(0.50-0.74)$ & $0.94(0.91-0.96)$ \\
\hline Serum PCT & {$[40]$} & 2018 & 6 & $0.58(0.31-0.81)$ & $0.95(0.63-1.00)$ \\
\hline Serum PCT & {$[22]$} & 2016 & 6 & $0.53(0.24-0.80)$ & $0.92(0.45-0.99)$ \\
\hline Serum WBC & [18] & 2010 & 15 & $0.45(0.41-0.49)$ & $0.87(0.85-0.89)$ \\
\hline Synovial fluid PCT & [28] & 2015 & 3 & $0.35(0.28-0.43)$ & $0.994(0.97-1.00)$ \\
\hline Synovial fluid GS & [45] & 2015 & 4 & $0.30(0.17-0.48)$ & $1.00(0.88-1.00)$ \\
\hline \multicolumn{6}{|l|}{ Intraoperative examination } \\
\hline Tissue PCR & {$[37]$} & 2013 & 5 & $0.95(0.91-0.99)$ & $0.81(0.66-0.90)$ \\
\hline Sonicate fluid BCB & {$[46]$} & 2018 & 4 & $0.85(0.77-0.91)$ & $0.86(0.81-0.91)$ \\
\hline Sonicate fluid PCR & [37] & 2013 & 4 & $0.81(0.71-0.91)$ & $0.96(0.92-1.00)$ \\
\hline Sonicate fluid & [47] & 2014 & 12 & $0.80(0.74-0.84)$ & $0.95(0.90-0.98)$ \\
\hline Sonicate fluid & [48] & 2017 & 16 & $0.79(0.76-0.81)$ & $0.95(0.94-0.96)$ \\
\hline Synovial fluid WCC/PMN\% & {$[31]$} & 2014 & 4 & $0.77(0.51-0.91)$ & $0.97(0.93-0.99)$ \\
\hline Sonicate fluid PCR & [49] & 2018 & 9 & $0.75(0.71-0.79)$ & $0.96(0.94-0.97)$ \\
\hline Tissue-frozen section [five leukocytes per high power field (400x)] & {$[50]$} & 2013 & 10 & $0.73(0.65-0.80)$ & $0.90(0.88-0.93)$ \\
\hline Tissue BCB & [51] & 2019 & 4 & $0.70(0.66-0.75)$ & $0.97(0.95-0.98)$ \\
\hline Tissue-frozen section [ten leukocytes per high power field (400x)] & [50] & 2013 & 5 & $0.64(0.54-0.74)$ & $0.95(0.93-0.97)$ \\
\hline Tissue GS & [45] & 2015 & 5 & $0.16(0.08-0.29)$ & $0.99(0.98-1.00)$ \\
\hline Tissue swab GS & [45] & 2015 & 3 & $0.14(0.07-0.24)$ & $1.00(0.97-1.00)$ \\
\hline
\end{tabular}


Table 10 Diagnostic methods used for PJl detection ranked by the sensitivity (preoperative examination, intraoperative methods, and test before reimplantation) (Continued)

\begin{tabular}{|c|c|c|c|c|c|}
\hline & Reference & Year & No. of studies & Sen $(95 \% \mathrm{Cl})$ & Spe $(95 \% \mathrm{Cl})$ \\
\hline \multicolumn{6}{|l|}{ Before reimplantation } \\
\hline Tissue culture & [52] & 2018 & 2 & $0.82(0.72-0.90)$ & $0.91(0.89-0.95)$ \\
\hline Synovial fluid PMN\% & {$[52]$} & 2018 & 2 & $0.77(0.46-0.95)$ & $0.74(0.67-0.81)$ \\
\hline Synovial fluid PMN\% & [53] & 2018 & 4 & $0.70(0.58-0.81)$ & $0.71(0.66-0.77)$ \\
\hline Synovial fluid culture & [52] & 2018 & 2 & $0.64(0.52-0.74)$ & $0.96(0.93-0.98)$ \\
\hline Serum ESR & [53] & 2018 & 5 & $0.57(0.45-0.68)$ & $0.50(0.45-0.56)$ \\
\hline Serum ESR & [52] & 2018 & 3 & $0.56(0.40-0.72)$ & $0.60(0.53-0.66)$ \\
\hline Serum CRP & [52] & 2018 & 3 & $0.53(0.39-0.67)$ & $0.72(0.66-0.78)$ \\
\hline Spacer sonicate fluid culture & {$[53]$} & 2018 & 4 & $0.53(0.38-0.68)$ & $0.84(0.76-0.90)$ \\
\hline Synovial fluid WBC & [53] & 2018 & 5 & $0.52(0.41-0.63)$ & $0.66(0.61-0.71)$ \\
\hline Serum CRP & [53] & 2018 & 8 & $0.45(0.36-0.55)$ & $0.73(0.69-0.77)$ \\
\hline Synovial fluid WBC & {$[52]$} & 2018 & 2 & $0.37(0.19-0.58)$ & $0.49(0.41-0.57)$ \\
\hline Tissue culture & [53] & 2018 & 9 & $0.30(0.23-0.38)$ & $0.90(0.87-0.92)$ \\
\hline Frozen section & {$[53]$} & 2018 & 4 & $0.29(0.17-0.44)$ & $0.93(0.89-0.96)$ \\
\hline Synovial fluid culture & [53] & 2018 & 5 & $0.18(0.11-0.28)$ & $0.97(0.94-0.99)$ \\
\hline
\end{tabular}

$A G S$ antigranulocyte scintigraphy, $B C B$ blood culture bottles, $C$ confidence interval, $C R P$ C-reactive protein, $C T$ computed tomography, ELISA enzyme-linked immunosorbent assays, ESR erythrocyte sedimentation, GS Gram staining, $L E$ leukocyte esterase, $I L$ interleukin, $P C R$ polymerase chain reaction, $P C T$ procalcitonin, $P E T$ positron emission tomography, $P M N \%$ polymorphonucleocyte percentage, Sen sensitivity, Spe specificity, WBC white blood cell, WCC white cell count

knee. Identical results were also found in regard to the location, with the top three keywords knee, hip, and shoulder. The most frequently used software in the meta-analysis were STATA, REVMAN, and MetaDisc.

Among the diagnosis list in meta-analysis studies, the synovial fluid test was the most frequently used preoperative examination (64\%). The most popular diagnostic test applied in recent years was synovial fluid alpha-defensin and has been incorporated in the 2018 Musculoskeletal Infection Society (MSIS) definition as one of the minor criteria [56]. When compared with conventional diagnostic methods, such as ESR, CRP, synovial fluid culture, and synovial fluid PMN\%, alpha-defensin showed better sensitivity, especially in cases receiving antibiotics before joint puncture [57, 58]. In recent years, synovial fluid alpha-defensin could be detected using two different methods. One assay is the enzyme-linked immunosorbent assay (ELISA), which is performed in a laboratory with results obtained within $24 \mathrm{~h}$. The second assay is the lateral flow device, which rapidly detects infection within $20 \mathrm{~min}$ without the need for a laboratory. Accordingly, pooled results supported the higher sensitivity of the synovial fluid alpha-defensin ELISA compared to the lateral flow test $[16,20,23,27]$. The current meta-analysis demonstrated synovial fluid alpha-defensin to have the highest sensitivity in the diagnosis of PJI. As it represents a nonmicrobiological test, it could be used as a reliable reference for intraoperative microbiological diagnosis. Preoperative tests with the lowest sensitivities were synovial fluid gram staining (GS), synovial fluid procalcitonin (PCT), serum white blood cells (WBCs), and serum PCT, which were all found to have a sensitivity of less than $60 \%$.

Sonicate fluid and periprosthetic tissue were performed most intraoperatively, whereas tissue PCR and sonicate fluid $\mathrm{BCB}$ were the most sensitive tests in tissue and sonicate fluid, respectively. In 2013, Qu et al. [37] performed the first meta-analysis of PCR in the diagnosis of PJI. The authors found that the tissue PCR had a higher sensitivity than synovial fluid PCR and sonicate fluid PCR ( $95 \%$ vs. $84 \%$ vs. $81 \%$, respectively). However, tissue PCR showed the lowest specificity compared to synovial and sonicate fluid PCR ( $81 \%$ vs. $89 \%$ vs. $96 \%$, respectively). However, this is in contrast to the study by Huang and colleagues [59], in which tissue PCR had lower sensitivity of $34 \%$ and the highest specificity of $100 \%$ among the three types. Due to limited data and that the included studies on tissue PCR were performed between 1999 and 2012 [37], the diagnostic value of tissue PCR remains unclear. The meta-analysis of sonicate fluid BCB presented a sensitivity of $85 \%$ and a specificity of $86 \%$ [46]. Compared to the conventional culture of sonicate fluid, $\mathrm{BCB}$ culture was more sensitive in 


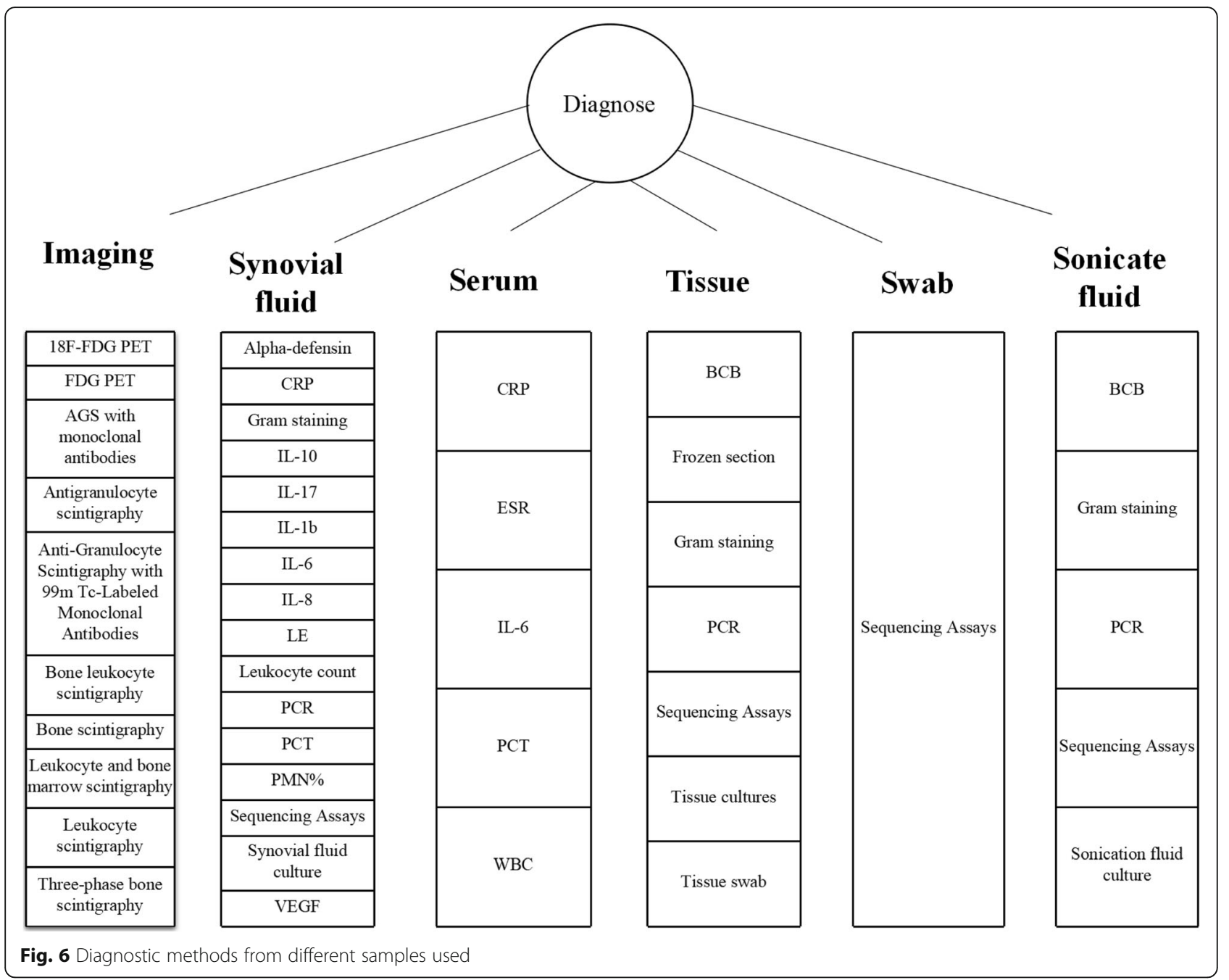

patients with or without antibiotics and also detected infection within a shorter time than normal medium sonicate fluid culture [60-63]. Yet, the drawback of sonicate fluid $\mathrm{BCB}$ was the rate of false-positives, which was caused by contamination during the inoculation procedure of $\mathrm{BCB}$ with sonicate fluid. Therefore, careful handling is required to minimize contamination $[64,65]$. Tissue and tissue swab GS were the two least frequently applied intraoperative tests, with a sensitivity of less than $20 \%$.

Diagnosis prior to reimplantation always posed difficulty. In the meta-analysis study by Lee and colleagues [52], tissue culture demonstrated the highest sensitivity before reimplantation, which was based on two included studies (82\%). Another meta-analysis study by Bian and co-workers [53] estimated the various tests during the first stage and/or predicted failed reimplantation beyond the second stage, with tissue culture showing a sensitivity of $30 \%$, which was based on the results of nine studies. Synovial fluid PMN\% demonstrated the highest sensitivity of $70 \%$ in the study by Bian et al., while the specificity was low at $71 \%$. Interestingly, the author found that the spacer sonication fluid culture was the most accurate method with an area under the receiver operating characteristic curve of 0.8089 . There was no single test that achieved an ideal result, with combined multiple tests to evaluate infection still required [53].

There were 40 meta-analyses related to risk factor and prevention, with the majority of articles on preventive measures focusing on systemic or location antibiotics use. In regard to the risk factor, most concerns focused on intra-articular steroid injections, followed by age, diabetes mellitus, and rheumatoid arthritis.

The top three comparison studies focused on cemented vs. cementless total joint arthroplasty, the outcome of using different types of spacers, and the outcome of one-stage vs. two-stage exchange. 
Table 11 Risk factors of PJl based on meta-analysis studies

The incidence of and risk factors for deep infection after
primary shoulder arthroplasty: an updated systematic review and meta-analysis

Allogeneic blood transfusion is a significant risk factor for surgical-site infection following total hip and knee arthroplasty: a meta-analysis

Association of malnutrition with periprosthetic joint and surgical site infections after total joint arthroplasty: a systematic review and meta-analysis

Current evidence does not support systematic antibiotherapy prior to joint arthroplasty in patients with asymptomatic bacteriuria-a meta analysis

Do intra-articular steroid injections increase infection rates in subsequent arthroplasty? A systematic review and metaanalysis of comparative studies

Does previous intra-articular steroid injection increase the risk of joint infection following total hip arthroplasty or total knee arthroplasty? A meta-analysis

Dose intraarticular steroid injection increase the rate of infection in subsequent arthroplasty: grading the evidence through a meta-analysis

Genetic susceptibility to prosthetic joint infection following total joint arthroplasty: a systematic review

Genetic susceptibility to prosthetic joint infection following total joint arthroplasty: a systematic review

Higher age, female gender, osteoarthritis and blood transfusion protect against periprosthetic joint infection in total hip or knee arthroplasties: a systematic review and meta-analysis

Inadequate glycemic control is associated with increased surgical site infection in total joint arthroplasty: a systematic review and meta-analysis

Incidence and risk factors for surgical site infection following total knee arthroplasty: a systematic review and meta-analysis

Incidence and risk factors for surgical site infection following total knee arthroplasty: a systematic review and meta-analysis

Intra-articular steroid injections and risk of infection following total hip replacement or total knee replacement: a metaanalysis of cohort studies

Is hemoglobin A1c and perioperative hyperglycemia predictive of periprosthetic joint infection following total joint arthroplasty?: A systematic review and meta-analysis

Meta-analysis shows that obesity may be a significant risk factor for prosthetic joint infections

Patient-related risk factors for periprosthetic joint infection after total joint arthroplasty: a systematic review and metaanalysis

Patient-related risk factors for periprosthetic joint infection after total joint arthroplasty: a systematic review and metaanalysis

Positive culture during reimplantation increases the risk of reinfection in two-stage exchange arthroplasty despite administrating prolonged antibiotics: a retrospective cohort study and meta-analysis

Preoperative malnutrition negatively correlates with postoperative wound complications and infection after total joint arthroplasty: a systematic review and meta-analysis

\begin{tabular}{|c|c|c|}
\hline Location & $\mathrm{Y} / \mathrm{N}$ & Topic \\
\hline Shoulder & Y & $\begin{array}{l}\text { Male gender, avascular necrosis } \\
\text { proximal humerus fracture, non }\end{array}$ \\
\hline Hip, knee & Y & Allogeneic blood transfusion \\
\hline $\begin{array}{l}\text { Hip, knee and } \\
\text { other undefined } \\
\text { location }\end{array}$ & Y & Malnutrition \\
\hline Hip, knee & Y & Asymptomatic bacteriuria \\
\hline Hip, knee & $\mathrm{N}$ & Intra-articular steroid injections \\
\hline Hip, knee & $\mathrm{N}$ & Intra-articular steroid injections \\
\hline
\end{tabular}

Hip, knee $\quad$ Y Intra-articular steroid injections

NA

NA

Hip, knee

Hip, knee, shoulder

Knee

Knee

Hip, knee

Hip, knee

Hip

NA

NA

Hip, knee

Hip, knee
Y C allele and genotype C/C for MBL-550SNP, genotype A/A for MBL-54SNP,G allele for MBL-221SNP

N G allele and genotype G/G for MBL-550SNP

Y Male gender, coagulopathy, alcohol abuse, surgical site infection (highest score), and high NNIS system surgical patient index score

Y Inadequate glycemic control

$\mathrm{N}$ Steroid use, bilateral surgery, drain usage, bone graft, urinary tract infection, hypertension, and rheumatoid arthritis

$Y \quad$ Male gender, age, obesity, smoking, American Society of Anesthesiologists scale (ASA) > 2, operative time, transfusion, diabetes mellitus, obesity

Y Intra-articular steroid injections

Y High $\mathrm{HbAlc}$ and perioperative hyperglycemia

Y Obesity

$\mathrm{N}$ Age, high alcohol intake

Y Histories of diabetes, rheumatoid arthritis, depression, steroid use, and previous joint surgery

Y Positive culture at reimplantation

Y Preoperative malnutrition 
Table 11 Risk factors of PJI based on meta-analysis studies (Continued)

\begin{tabular}{|c|c|c|c|}
\hline Title & Location & $\mathrm{Y} / \mathrm{N}$ & Topic \\
\hline $\begin{array}{l}\text { Risk factors for deep infection after total knee arthroplasty: a } \\
\text { meta-analysis }\end{array}$ & Knee & Y & $\begin{array}{l}\text { BMl, diabetes mellitus, hypertension, steroid therapy, } \\
\text { rheumatoid arthritis }\end{array}$ \\
\hline $\begin{array}{l}\text { Risk factors for deep infection after total knee arthroplasty: a } \\
\text { meta-analysis }\end{array}$ & Knee & $\mathrm{N}$ & $\begin{array}{l}\text { Gender, osteoarthritis, urinary tract infection, fixation method, } \\
\text { American Society of Anesthesiologists, bilateral operation, } \\
\text { age, transfusion, antibiotics, bone graft }\end{array}$ \\
\hline $\begin{array}{l}\text { Risk factors for periprosthetic joint infection after hip or knee } \\
\text { arthroplasty in mainland of China: a meta-analysis }\end{array}$ & Hip, knee & Y & $\begin{array}{l}\text { Diabetes mellitus, long-term use of steroids, long operation } \\
\text { time ( }>90 \mathrm{~min}) \text {, age ( }>65 \text { years), and previous history of hip } \\
\text { or knee surgery }\end{array}$ \\
\hline $\begin{array}{l}\text { Risk factors for periprosthetic joint infection after total joint } \\
\text { arthroplasty: a systematic review and meta-analysis }\end{array}$ & NA & Y & $\begin{array}{l}\text { Body mass index, diabetes mellitus; corticosteroid therapy, } \\
\text { hypoalbuminemia, history of rheumatoid arthritis, blood } \\
\text { transfusion, presence of a wound drain, wound dehiscence, } \\
\text { superficial surgical site infection, coagulopathy, malignancy, } \\
\text { immunodepression, National Nosocomial Infections } \\
\text { Surveillance Score } \geq 2 \text {, other nosocomial infection, prolonged } \\
\text { operative time, previous surgery }\end{array}$ \\
\hline $\begin{array}{l}\text { Risk factors for periprosthetic joint infection after total joint } \\
\text { arthroplasty: a systematic review and meta-analysis }\end{array}$ & NA & $\mathrm{N}$ & $\begin{array}{l}\text { Cirrhosis, hypothyroidism, urinary tract infection, illicit drug } \\
\text { abuse, alcohol abuse, hypercholesterolemia, hypertension, } \\
\text { ischemic heart disease, peptic ulcer disease, hemiplegia or } \\
\text { paraplegia, dementia, operation performed by a staff surgeon } \\
\text { (vs. a trainee) }\end{array}$ \\
\hline $\begin{array}{l}\text { Risk of surgical site infection in patients with asymptomatic } \\
\text { bacteriuria or abnormal urinalysis before joint arthroplasty: } \\
\text { systematic review and meta-analysis }\end{array}$ & Hip, knee & Y & Asymptomatic bacteriuria \\
\hline $\begin{array}{l}\text { Tobacco use and risk of wound complications and } \\
\text { periprosthetic joint infection: a systematic review and meta- } \\
\text { analysis of primary total joint arthroplasty procedures }\end{array}$ & Hip, knee & Y & Tobacco \\
\hline $\begin{array}{l}\text { Total joint arthroplasty following intra-articular steroid injec- } \\
\text { tion: a literature review }\end{array}$ & Hip, knee & $\mathrm{N}$ & Intra-articular steroid injections \\
\hline
\end{tabular}

$\boldsymbol{N A}$ not available, $\boldsymbol{N}$ the present study supported the topic not to be a risk factor of $\mathrm{PJI}, \boldsymbol{Y}$ the present study supported the topic not to be a risk factor of PJI

Cemented fixations were revealed to increase the overall PJI risk in comparison to uncemented fixations [66-68]. Interestingly, there was no significant difference in the eradication rate between articulating and static spacers in the infected knee replacement $[69,70]$. The current meta-analysis supports that the infection control or reinfection rate of one-stage or two-stage exchange did not significantly differ in the hip, knee, elbow, and shoulder [71-75].

There are several limitations to the present study. First, the database of present bibliometric analyses was collected from three databases. Compared with results from without the search strategy, several articles were missed when using the search strategy, especially in PubMed. However, working with multiple databases could reduce this problem. In addition, we also collected database information from all metaanalyses. Embase, MEDLINE, and Cochrane were the most widely used databases. However, whether these databases were appropriate for bibliometric analysis remains unclear and requires further investigation. Second, due to the export of all meta-analysis information between different databases with disparate formats, a visualized analysis could not be performed. Third, although meta-analysis results on diagnosis, risk factors, prevention, and comparative studies were shown, the heterogeneity and quality of included meta-analysis studies were not considered. In the subgroup diagnosis, since there is no gold standard for the diagnosis of PJI, different culture results are obtained from the various diagnostics tests. The pooled sensitivity and specificity of meta-analysis are then further affected by potential false positive or negative results. Fourth, the current study only presented metaanalysis results and did not reflect the complete perspective of PJI research. The overall trends in this field are required to further confirm.

\section{Conclusion}

The bibliometric analysis that presented global PJI research of meta-analysis studies showed an increasing trend between 2007 and 2019. The Embase database and STATA software were most frequently used for metaanalysis. Most studies focused on the periprosthetic hip and knee. The diagnostic alpha-defensin test, preventive measures on antibiotics use, and risk factors associated with intra-articular steroid injections were the most popular topics in recent years. 
Table 12 Prevention of PJl based on meta-analysis research

\begin{tabular}{|c|c|c|c|}
\hline Title & Location & $\begin{array}{l}\mathrm{Y} / \\
\mathrm{N}\end{array}$ & Topic \\
\hline $\begin{array}{l}\text { Negative pressure wound therapy in total hip and knee arthroplasty: a } \\
\text { meta-analysis }\end{array}$ & Hip, knee & Y & Negative pressure wound therapy \\
\hline $\begin{array}{l}\text { A systematic review and meta-analysis of antibiotic-impregnated bone } \\
\text { cement use in primary total hip or knee arthroplasty }\end{array}$ & Hip, knee & Y & Antibiotic-impregnated bone cement \\
\hline $\begin{array}{l}\text { Antibiotic bone cement's effect on infection rates in primary and } \\
\text { revision total knee arthroplasties }\end{array}$ & Knee & $\mathrm{N}$ & Antibiotic-impregnated bone cement \\
\hline $\begin{array}{l}\text { Antibiotic prophylaxis for wound infections in total joint arthroplasty: } \\
\text { a systematic review }\end{array}$ & $\begin{array}{l}\text { Hip, knee, and } \\
\text { other undefined } \\
\text { location }\end{array}$ & Y & Antibiotic prophylaxis \\
\hline $\begin{array}{l}\text { Antibiotic-impregnated bone cement for preventing infection in } \\
\text { patients receiving primary total hip and knee arthroplasty: a meta- } \\
\text { analysis }\end{array}$ & Hip, knee & Y & Antibiotic-impregnated bone cement \\
\hline $\begin{array}{l}\text { Control strategies to prevent total hip replacement-related infections: } \\
\text { a systematic review and mixed treatment comparison }\end{array}$ & Hip & Y & $\begin{array}{l}\text { Systemic antibiotic prophylaxis in conjunction with } \\
\text { antibiotic-impregnated cement and conventional } \\
\text { ventilation }\end{array}$ \\
\hline $\begin{array}{l}\text { Efficacy of antibiotic-impregnated cement in total hip replacement: a } \\
\text { meta-analysis }\end{array}$ & Hip & Y & Antibiotic-impregnated bone cement \\
\hline $\begin{array}{l}\text { Efficacy of prophylactic cefazoline and vancomycin in hip and knee } \\
\text { surgery: a systematic review and meta-analysis }\end{array}$ & Hip, knee & Y & Antibiotic prophylaxis \\
\hline $\begin{array}{l}\text { Lack of efficacy of prophylactic application of antibiotic-loaded bone } \\
\text { cement for prevention of infection in primary total knee arthroplasty: } \\
\text { results of a meta-analysis }\end{array}$ & Knee & $\mathrm{N}$ & Antibiotic-impregnated bone cement \\
\hline $\begin{array}{l}\text { Perioperative antibiotic prophylaxis in total joint arthroplasty: a } \\
\text { systematic review and meta-analysis }\end{array}$ & Hip, knee & $\mathrm{N}$ & $\begin{array}{l}\text { Postoperative antibiotic prophylaxis or continuation } \\
\text { beyond } 24 \mathrm{~h}\end{array}$ \\
\hline $\begin{array}{l}\text { Postoperative antibiotic prophylaxis in total hip and knee arthroplasty: } \\
\text { a systematic review and meta-analysis of randomized controlled trials }\end{array}$ & Hip, knee & $\mathrm{N}$ & Postoperative antibiotic prophylaxis \\
\hline $\begin{array}{l}\text { Preoperative bathing with chlorhexidine reduces the incidence of } \\
\text { surgical site infections after total knee arthroplasty }\end{array}$ & Knee & Y & Chlorhexidine \\
\hline $\begin{array}{l}\text { Preoperative chlorhexidine reduces the incidence of surgical site } \\
\text { infections in total knee and hip arthroplasty: a systematic review and } \\
\text { meta-analysis }\end{array}$ & Hip, knee & Y & Chlorhexidine \\
\hline $\begin{array}{l}\text { Prophylaxis with nasal decolonization in patients submitted to total } \\
\text { knee and hip arthroplasty: systematic review and meta-analysis }\end{array}$ & Hip, knee & Y & Prophylaxis with nasal decolonization \\
\hline $\begin{array}{l}\text { Systematic review and meta-analysis of randomized controlled trials of } \\
\text { antibiotics and antiseptics for preventing infection in people receiving } \\
\text { primary total hip and knee prostheses }\end{array}$ & Hip, knee & $\mathrm{N}$ & Antibiotics and/or antiseptics \\
\hline $\begin{array}{l}\text { The hidden cost of commercial antibiotic-loaded bone cement: a sys- } \\
\text { tematic review of clinical results and cost implications following total } \\
\text { knee arthroplasty }\end{array}$ & Knee & $\mathrm{N}$ & Antibiotic-impregnated bone cement \\
\hline
\end{tabular}

$N$ the present study did not support the topic to be an effective prevention measure for PJl, $Y$ the present study supported the topic to be an effective prevention measure for PJI 
Table 13 Comparison studies of PJI based on meta-analysis

\begin{tabular}{ll}
\hline Title & Lo \\
\hline Infection and revision rates following primary total knee & Kn \\
arthroplasty in patients with rheumatoid arthritis versus & \\
osteoarthritis: a meta-analysis & \\
Simultaneous versus staged bilateral total knee arthroplasty & Kn \\
a meta-analysis evaluating mortality, peri-operative complica- \\
tions and infection rates \\
Comparison of infection eradication rate of using articulating \\
spacers containing bio-inert materials versus all-cement ar- \\
ticulating spacers in revision of infected TKA: a systematic re- \\
view and meta-analysis
\end{tabular}

Comparison of the efficacy of static versus articular spacers in two-stage revision surgery for the treatment of infection following total knee arthroplasty: a meta-analysis

Do culture-negative periprosthetic joint infections have a worse outcome than culture-positive periprosthetic joint infections? A systematic review and meta-analysis

Does cemented or cementless single-stage exchange arthro- Hip plasty of chronic periprosthetic hip infections provide similar infection rates to a two-stage? A systematic review

Does simultaneous bilateral total joint arthroplasty increase deep infection risk compared to staged surgeries? A metaanalysis

Dynamic versus static cement spacer in periprosthetic knee infection: a meta-analysis [Dynamischer vs. statischer

Zementspacer in der Knietotalendoprotheseninfektion: Eine Metaanalyse]

External fixation vs intramedullary nailing for knee arthrodesis after failed infected total knee arthroplasty: a systematic review and meta-analysis

Implant fixation and risk of prosthetic joint infection following primary total hip replacement: meta-analysis of observational cohort and randomised intervention studies

Influence of fixation methods on prosthetic joint infection following primary total knee replacement: meta-analysis of observational cohort and randomised intervention studies

One- and two-stage surgical revision of infected elbow prostheses following total joint replacement: a systematic review

One- and two-stage surgical revision of infected shoulder prostheses following arthroplasty surgery: a systematic review and meta-analysis

One- and two-stage surgical revision of peri-prosthetic joint infection of the hip: a pooled individual participant data analysis of 44 cohort studies

Postoperative deep infection after cemented versus cementless total hip arthroplasty: a meta-analysis

Re-infection outcomes following one- and two-stage surgical revision of infected hip prosthesis: a systematic review and meta-analysis

Re-infection outcomes following one- and two-stage surgical Knee revision of infected knee prosthesis: a systematic review and meta-analysis

Re-infection rates and clinical outcomes following arthrodesis with intramedullary nail and external fixator for infected knee prosthesis: a systematic review and metaanalysis

Knee

Location Topic

Rheumatoid arthritis

风 Osteoarthritis

Knee

Knee

materials

Simultaneous bilateral total knee arthroplasty

Articulating spacers

Hip, Culture-positive infections

knee

Single-stage exchange

Single-stage cementless

Hip, Staged bilateral total joint arthroplasty

knee

Knee

Dynamic knee spacer

Knee

External fixation

Hip Cemented fixations (plain and antibiotic combined, plain cemented fixations, hybrid fixations, reverse hybrid fixations)

Knee Cemented fixations (plain and antibiotic combined, plain cemented fixations, hybrid fixations, reverse hybrid fixations)

Elbow Single-stage exchange

Shoulder Single-stage exchange

Hip

Single-stage exchange

Hip Cemented total hip arthroplasty

Single-stage exchange (unselected patients)

Single-stage exchange (unselected patients)

Knee Arthrodesis with intramedullary nail
Staged bilateral

total knee arthroplasty

邓 All-cement articulating spacers

Static spacers

Culture-negative infections

Two-stage exchange

Single-stage cemented

凶 Simultaneous bilateral total joint arthroplasty

Static knee spacer

Intramedullary nailing

凶 Uncemented fixations

凶 Uncemented fixations

Two-stage exchange

Two-stage exchange

Two-stage exchange

凶 Cementless total hip arthroplasty

Two-stage exchange (unselected patients)

Two-stage exchange (unselected patients)

邓 Arthrodesis with external fixator 
Table 13 Comparison studies of PJl based on meta-analysis (Continued)

\begin{tabular}{|c|c|c|c|c|c|}
\hline Title & Location & Topic & & & \\
\hline $\begin{array}{l}\text { Use of static or articulating spacers for infection following } \\
\text { total knee arthroplasty }\end{array}$ & Knee & Articulating spacers & & Static spacers & \\
\hline $\begin{array}{l}\text { The effect of wound dressings on infection following total } \\
\text { joint arthroplasty }\end{array}$ & $\begin{array}{l}\text { Hip, } \\
\text { knee }\end{array}$ & Standard, absorbent dressings & 凶 & $\begin{array}{l}\text { Hydrofiber } \\
\text { dressings }\end{array}$ & $\nabla$ \\
\hline $\begin{array}{l}\text { Human immunodeficiency virus and total joint arthroplasty: } \\
\text { the risk for infection is reduced }\end{array}$ & $\begin{array}{l}\text { Hip, } \\
\text { knee }\end{array}$ & HIV and hemophilia & 凶 & HIV & $\nabla$ \\
\hline $\begin{array}{l}\text { The impact of neuraxial versus general anesthesia on the } \\
\text { incidence of postoperative surgical site infections following } \\
\text { knee or hip arthroplasty a meta-analysis }\end{array}$ & $\begin{array}{l}\text { Hip, } \\
\text { knee }\end{array}$ & General anesthesia & 凶 & $\begin{array}{l}\text { Neuraxial } \\
\text { anesthesia }\end{array}$ & $\nabla$ \\
\hline $\begin{array}{l}\text { Tobacco use and risk of wound complications and } \\
\text { periprosthetic joint infection: a systematic review and meta- } \\
\text { analysis of primary total joint arthroplasty procedures }\end{array}$ & $\begin{array}{l}\text { Hip, } \\
\text { knee }\end{array}$ & Current tobacco users & 凶 & $\begin{array}{l}\text { Former tobacco } \\
\text { users }\end{array}$ & $\nabla$ \\
\hline
\end{tabular}

: The meta-analysis results showed that there was no significant relationship between the two topics. $\mathbf{X}$ : The meta-analysis results demonstrated that the topic had a higher infection/reinfection rate, further compounded results, represented a risk factor, or was not an effective method of preventing infection; $\square$ : The meta-analysis results showed that the topic had a lower infection rate/reinfection rate, more optimal result, represented an effective prevention measure against infection, or was not a risk factor

\section{Supplementary information}

Supplementary information accompanies this paper at https://doi.org/10. 1186/s13018-020-01757-9.

Additional file 1:. Supplementary S1.

\section{Abbreviations}

AGS: Antigranulocyte scintigraphy; BCB: Blood culture bottles; CAOS: Chinese Association of Orthopaedic Surgeons; Cl: Confidence interval; CRP: C-reactive protein; CT: Computed tomography; ELISA: Enzyme-linked immunosorbent assays; ESR: Erythrocyte sedimentation; GS: Gram staining; LE: Leukocyte esterase; IL: Interleukin; PCR: Polymerase chain reaction; PCT: Procalcitonin; PET: Positron emission tomography; PJl: Periprosthetic joint infection; PMN\%: Polymorphonucleocytes percentage; Sen: Sensitivity; Spe: Specificity; MeSH: Medical subject headings; MSIS: Musculoskeletal Infection Society; WBCs: White blood cells; WCC: White cell count

\section{Acknowledgements}

This work was supported by the PRO-IMPLANT Foundation, Berlin, Germany (https://www.pro-implant.org), a non-profit organization supporting research, education, global networking and care of patients with bone, joint, or implant-associated infection.

\section{Authors' contributions}

LC searched the database, participated in data analysis, and helped draft the manuscript. COT and XC proposed the study design and participated in data analysis. AT edited and reviewed the manuscript. All authors have seen and approved the final version of the paper before submission.

\section{Funding}

PRO-IMPLANT Foundation

\section{Availability of data and materials}

Data was extracted from references.

\section{Ethics approval and consent to participate}

Not applicable

\section{Consent for publication}

Not applicable

\section{Competing interests}

The authors declare that they have no competing interests.

\section{Author details}

${ }^{1}$ Charité-Universitätsmedizin Berlin, corporate member of Freie Universität Berlin, Humboldt-Universität zu Berlin, and Berlin Institute of Health, Center for Musculoskeletal Surgery (CMSC), Charitéplatz 1, D-10117 Berlin, Germany. ${ }^{2}$ Hospital Universitario 12 de Octubre, Madrid, Spain. ${ }^{3}$ Department of Orthopaedic Surgery, General Hospital of People's Liberation Army, Beijing, People's Republic of China.

Received: 19 March 2020 Accepted: 16 June 2020

Published online: 10 July 2020

References

1. Li C, Renz N, Trampuz A, Ojeda-Thies C. Twenty common errors in the diagnosis and treatment of periprosthetic joint infection. Int Orthop. 2019; Available from: http://dx.doi.org/https://doi.org/10.1007/s00264-019-04426-7.

2. Wang K, Xing D, Dong S, Lin J. The global state of research in nonsurgical treatment of knee osteoarthritis: a bibliometric and visualized study. BMC Musculoskelet Disord. 2019;20:407.

3. Ahmad SS, Evangelopoulos DS, Abbasian M, Röder C, Kohl S. The hundred most-cited publications in orthopaedic knee research. J Bone Joint Surg Am. 2014;96:e190.

4. Çevik HB, Gümüştaş SA. Fifty top-cited classic papers in orthopaedic oncology: a bibliometric analysis. Arch Orthop Trauma Surg. 2019;139: 1187-92.

5. Li M, Zeng Y, Wu Y, Si H, Bao X, Shen B. Performance of sequencing assays in diagnosis of prosthetic joint infection: a systematic review and metaanalysis. J Arthroplast. 2019;34:1514-1522.e4.

6. Shohat N, Muhsen K, Gilat R, Rondon AJ, Chen AF, Parvizi J. Inadequate glycemic control is associated with increased surgical site infection in total joint arthroplasty: a systematic review and meta-analysis. J Arthroplast. 2018; 33:2312-21.e3.

7. Guilera G, Barrios M, Gómez-Benito J. Meta-analysis in psychology: a bibliometric study. Scientometrics. 2013;94:943-54.

8. Pereira RS, Santos IC, Oliveira KDS, Leão NCA. Meta-analysis as a research tool: a systematic review of bibliometric studies in administration. RAM, Rev Adm Mackenzie. Universidade Presbiteriana Mackenzie; 2019;20. Available from: http://www.scielo.br/scielo.php?script=sci_arttext\&pid=\$1678-6971201 9000500301\&tlng=en.

9. Kumar A, Gupta BM, Goel S, Bansal J. Hip replacement surgery: a scientometric assessment of global publications output during 2007-16. Internatio Journ of Inform Dissemin and Techno. 2018;8:25.

10. Aggarwal A, Lewison G, Idir S, Peters M, Aldige C, Boerckel W, et al. The state of lung cancer research: a global analysis. J Thorac Oncol. 2016;11: 1040-50.

11. AlRyalat SAS, Malkawi LW, Momani SM. Comparing bibliometric analysis using PubMed, Scopus, and web of science databases. J Vis Exp 2019; Available from: http://dx.doi.org/https://doi.org/10.3791/58494. 
12. AlBuhairan B, Hind D, Hutchinson A. Antibiotic prophylaxis for wound infections in total joint arthroplasty: a systematic review. J Bone Joint Surg Br. 2008;90:915-9.

13. Parvizi J, Saleh KJ, Ragland PS, Pour AE, Mont MA. Efficacy of antibioticimpregnated cement in total hip replacement. Acta Orthop. 2008;79:335-41.

14. Wyatt MC, Beswick AD, Kunutsor SK, Wilson MJ, Whitehouse MR, Blom AW The alpha-defensin immunoassay and leukocyte esterase colorimetric strip test for the diagnosis of periprosthetic infection: a systematic review and meta-analysis. J Bone Joint Surg Am. 2016;98:992-1000.

15. Li B, Chen F, Liu Y, Xu G. Synovial fluid a-defensin as a biomarker for periprosthetic joint infection: a systematic review and meta-analysis. Surg Infect. 2017;18:702-10.

16. Balato G, de Matteo V, Ascione T, Di Donato SL, De Franco C, Smeraglia F, et al. Laboratory-based versus qualitative assessment of a-defensin in periprosthetic hip and knee infections: a systematic review and metaanalysis. Arch Orthop Trauma Surg. 2020;140:293-301.

17. Lee YS, Koo K-H, Kim HJ, Tian S, Kim T-Y, Maltenfort MG, et al. Synovial fluid biomarkers for the diagnosis of periprosthetic joint infection: a systematic review and meta-analysis. J Bone Joint Surg Am. 2017;99:2077-84.

18. Berbari E, Mabry T, Tsaras G, Spangehl M, Erwin PJ, Murad MH, et al. Inflammatory blood laboratory levels as markers of prosthetic joint infection: a systematic review and meta-analysis. J Bone Joint Surg Am. 2010;92:2102-9.

19. Ahmad SS, Hirschmann MT, Becker R, Shaker A, Ateschrang A, Keel MJB, et al. A meta-analysis of synovial biomarkers in periprosthetic joint infection: Synovasure $^{\mathrm{TM}}$ is less effective than the ELISA-based alpha-defensin test. Knee Surg Sports Traumatol Arthrosc. 2018;26:3039-47.

20. Eriksson HK, Nordström J, Gabrysch K, Hailer NP, Lazarinis S. Does the alphadefensin immunoassay or the lateral flow test have better diagnostic value for periprosthetic joint infection? A meta-analysis. Clin Orthop Relat Res. 2018;476:1065-72.

21. Yuan J, Yan Y, Zhang J, Wang B, Feng J. Diagnostic accuracy of alphadefensin in periprosthetic joint infection: a systematic review and metaanalysis. Int Orthop. 2017:41:2447-55.

22. Xie K, Qu X, Yan M. Procalcitonin and a-defensin for diagnosis of periprosthetic joint infections. J Arthroplast. 2017:32:1387-94

23. Suen K, Keeka M, Ailabouni R, Tran P. Synovasure "quick test" is not as accurate as the laboratory-based a-defensin immunoassay: a systematic review and meta-analysis. Bone Joint J. 2018;100-B:66-72.

24. Marson BA, Deshmukh SR, Grindlay DJC, Scammell BE. Alpha-defensin and the Synovasure lateral flow device for the diagnosis of prosthetic joint infection: a systematic review and meta-analysis. Bone Joint J. 2018;100-B: 703-11.

25. Verberne SJ, Sonnega RJA, Temmerman OPP, Raijmakers PG. What is the accuracy of nuclear imaging in the assessment of periprosthetic knee infection? A meta-analysis. Clin Orthop Relat Res. 2017:475:1395-410.

26. Wang C, Wang Q, Li R, Duan J-Y, Wang C-B. Synovial fluid C-reactive protein as a diagnostic marker for periprosthetic joint infection: a systematic review and meta-analysis. Chin Med J. 2016;129:1987-93.

27. Chen Y, Kang X, Tao J, Zhang Y, Ying C, Lin W. Reliability of synovial fluid alpha-defensin and leukocyte esterase in diagnosing periprosthetic joint infection (PJI): a systematic review and meta-analysis. J Orthop Surg Res. 2019:14:453.

28. He P, Li S, Huang S, Wa Q, Xu D. Biomarker screening of periprosthetic joint infection and establishment of diagnostic model. J Comput Theor Nanosci. 2015;12:4127-31.

29. De Fine M, Giavaresi G, Fini M, Illuminati A, Terrando S, Pignatti G. The role of synovial fluid analysis in the detection of periprosthetic hip and knee infections: a systematic review and meta-analysis. Int Orthop. 2018:42:983-94

30. Xie K, Dai K, Qu X, Yan M. Serum and synovial fluid interleukin- 6 for the diagnosis of periprosthetic joint infection. Sci Rep. 2017;7:1496.

31. Qu X, Zhai Z, Liu X, Li H, Wu C, Li Y, et al. Evaluation of white cell count and differential in synovial fluid for diagnosing infections after total hip or knee arthroplasty. PLoS One. 2014;9:e84751

32. Wang C, Li R, Wang Q, Wang C. Synovial fluid leukocyte esterase in the diagnosis of peri-prosthetic joint infection: a systematic review and metaanalysis. Surg Infect. 2018;19:245-53.

33. Verberne SJ, Raijmakers PG, Temmerman OPP. The accuracy of imaging techniques in the assessment of periprosthetic hip infection: a systematic review and meta-analysis. J Bone Joint Surg Am. 2016;98:1638-45.
34. Hao R, Yuan L, Kan Y, Yang J. 18F-FDG PET for diagnosing painful arthroplasty/prosthetic joint infection. Clin Translational Imaging. 2017:5: 315-22.

35. Huerfano E, Bautista M, Huerfano M, Bonilla G, Llinas A. Screening for infection before revision hip arthroplasty: a meta-analysis of likelihood ratios of erythrocyte sedimentation rate and serum C-reactive protein levels. J Am Acad Orthop Surg. 2017;25:809-17

36. Liu X, Liang J, Li J-H, Ran Q-L, Liu L-S, Jiang L, et al. Diagnostic performance of 18F-FDG PET or PET-CT in multiple myeloma: a systematic review and meta-analysis. J Nucl Med Radiat Ther. OMICS International; 2016:7:1-8 - 8.

37. Qu X, Zhai Z, Li H, Li H, Liu X, Zhu Z, et al. PCR-based diagnosis of prosthetic joint infection. J Clin Microbiol. 2013;51:2742-6.

38. Pakos EE, Trikalinos TA, Fotopoulos AD, loannidis JPA. Prosthesis infection: diagnosis after total joint arthroplasty with antigranulocyte scintigraphy with $99 \mathrm{mTc}$-labeled monoclonal antibodies--a meta-analysis. Radiology. 2007;242:101-8.

39. Xing D, Ma X, Ma J, Wang J, Chen Y, Yang Y. Use of anti-granulocyte scintigraphy with $99 \mathrm{mTc}$-labeled monoclonal antibodies for the diagnosis of periprosthetic infection in patients after total joint arthroplasty: a diagnostic meta-analysis. PLoS One. 2013;8:e69857.

40. Yoon J-R, Yang S-H, Shin Y-S. Diagnostic accuracy of interleukin-6 and procalcitonin in patients with periprosthetic joint infection: a systematic review and meta-analysis. Int Orthop. 2018;42:1213-26.

41. Ouyang Z, Li H, Liu X, Zhai Z, Li X. Prosthesis infection: diagnosis after total joint arthroplasty with three-phase bone scintigraphy. Ann Nucl Med. 2014; 28:994-1003.

42. Kwee TC, Kwee RM, Alavi A. FDG-PET for diagnosing prosthetic joint infection: systematic review and metaanalysis. Eur J Nucl Med Mol Imaging. 2008:35:2122-32

43. Yuan $\mathrm{K}$, Chen $\mathrm{H}-\mathrm{L}$, Cui Z-M. Diagnostic accuracy of C-reactive protein for periprosthetic joint infection: a meta-analysis. Surg Infect . 2014;15:548-559.

44. Qu X, Zhai Z, Wu C, Jin F, Li H, Wang L, et al. Preoperative aspiration culture for preoperative diagnosis of infection in total hip or knee arthroplasty. J Clin Microbiol. 2013;51:3830-4.

45. Ouyang Z, Zhai Z, Qin AN, Li H, Liu X, Qu X, et al. Limitations of gram staining for the diagnosis of infections following total hip or knee arthroplasty. Exp Ther Med. 2015:9:1857-64.

46. Li C, Renz N, Thies CO, Trampuz A. Meta-analysis of sonicate fluid in blood culture bottles for diagnosing periprosthetic joint infection. J Bone Jt Infect. 2018;3:273-9.

47. Zhai Z, Li H, Qin A, Liu G, Liu X, Wu C, et al. Meta-analysis of sonication fluid samples from prosthetic components for diagnosis of infection after total joint arthroplasty. J Clin Microbiol. 2014;52:1730-6.

48. Liu H, Zhang Y, Li L, Zou HC. The application of sonication in diagnosis of periprosthetic joint infection. Eur J Clin Microbiol Infect Dis. 2017;36:1-9.

49. Liu K, Fu J, Yu B, Sun W, Chen J, Hao L. Meta-analysis of sonication prosthetic fluid PCR for diagnosing periprosthetic joint infection. PLoS One. 2018:13:e0196418.

50. Zhao X, Guo C, Zhao G-S, Lin T, Shi Z-L, Yan S-G. Ten versus five polymorphonuclear leukocytes as threshold in frozen section tests for periprosthetic infection: a meta-analysis. J Arthroplast. 2013;28:913-7.

51. Li C, Ojeda-Thies C, Trampuz A. Culture of periprosthetic tissue in blood culture bottles for diagnosing periprosthetic joint infection. BMC Musculoskelet Disord. 2019;20:299.

52. Lee YS, Fernando N, Koo K-H, Kim HJ, Vahedi H, Chen AF. What markers best guide the timing of reimplantation in two-stage exchange arthroplasty for PJI? A systematic review and meta-analysis. Clin Orthop Relat Res. 2018; 476:1972-83.

53. Bian $T$, Shao $H$, Zhou $Y$, Huang $Y$, Song $Y$. Tests for predicting reimplantation success of two-stage revision for periprosthetic joint infection: a systematic review and meta-analysis. Orthop Traumatol Surg Res. 2018:104:1115-23.

54. Parvizi J, Gehrke T, Chen AF. Proceedings of the international consensus on Periprosthetic joint infection. Bone Joint J. 2013;95-B:1450-2.

55. Yuan H-F, Xu W-D, Hu H-Y. Young Chinese doctors and the pressure of publication. Lancet. 2013;381:e4.

56. Parvizi J, Tan TL, Goswami K, Higuera C, Della Valle C, Chen AF, et al. The 2018 definition of periprosthetic hip and knee infection: an evidence-based and validated criteria. J Arthroplast. 2018;33:1309-1314.e2. 
57. Shahi A, Parvizi J, Kazarian GS, Higuera C, Frangiamore S, Bingham J, et al. The alpha-defensin test for periprosthetic joint infections is not affected by prior antibiotic administration. Clin Orthop Relat Res. 2016;474:1610-5.

58. Berger P, Van Cauter M, Driesen R, Neyt J, Cornu O, Bellemans J. Diagnosis of prosthetic joint infection with alpha-defensin using a lateral flow device: a multicentre study. Bone Joint J. 2017;99-B:1176-82.

59. Huang Z, Wu Q, Fang X, Li W, Zhang C, Zeng H, et al. Comparison of culture and broad-range polymerase chain reaction methods for diagnosing periprosthetic joint infection: analysis of joint fluid, periprosthetic tissue, and sonicated fluid. Int Orthop. 2018;42:2035-40.

60. Portillo ME, Salvadó M, Trampuz A, Siverio A, Alier A, Sorli L, et al. Improved diagnosis of orthopedic implant-associated infection by inoculation of sonication fluid into blood culture bottles. J Clin Microbiol. 2015;53:1622-7.

61. Janz V, Trampuz A, Perka CF, Wassilew Gl. Reduced culture time and improved isolation rate through culture of sonicate fluid in blood culture bottles. Technol Health Care. 2017;25:635-40.

62. Janz V, Wassilew Gl, Hasart O, Matziolis G, Tohtz S, Perka C. Evaluation of sonicate fluid cultures in comparison to histological analysis of the periprosthetic membrane for the detection of periprosthetic joint infection. Int Orthop. 2013;37:931-6.

63. Shen $H$, Tang J, Wang $Q$, Jiang $Y$, Zhang X. Sonication of explanted prosthesis combined with incubation in BD bactec bottles for pathogen-based diagnosis of prosthetic joint infection. J Clin Microbiol. 2015;53:777-81

64. Sanabria A, Røkeberg MEO, Johannessen M, Sollid JE, Simonsen GS, Hanssen A-M. Culturing periprosthetic tissue in BacT/alert ${ }^{\circledR}$ Virtuo blood culture system leads to improved and faster detection of prosthetic joint infections. BMC Infect Dis. 2019;19:607.

65. Yan Q, Karau MJ, Greenwood-Quaintance KE, Mandrekar JN, Osmon DR, Abdel MP, et al. Comparison of diagnostic accuracy of periprosthetic tissue culture in blood culture bottles to that of prosthesis sonication fluid culture for diagnosis of prosthetic joint infection (PJI) by use of Bayesian latent class modeling and IDSA PJI criteria for classification. J Clin Microbiol [Internet]. 2018;56. Available from: http://dx.doi.org/ https://doi.org/10.1128/JCM.00319-18.

66. George DA, Logoluso N, Castellini G, Gianola S, Scarponi S, Haddad FS, et al. Does cemented or cementless single-stage exchange arthroplasty of chronic periprosthetic hip infections provide similar infection rates to a twostage? A systematic review. BMC Infect Dis. 2016;16:553.

67. Kunutsor SK, Beswick AD, Whitehouse MR, Blom AW, Lenguerrand E. Implant fixation and risk of prosthetic joint infection following primary total hip replacement: meta-analysis of observational cohort and randomised intervention studies. J Clin Med Res 2019;8. Available from: http://dx.doi.org/ https://doi.org/10.3390/jcm8050722.

68. Kunutsor SK, Wylde V, Whitehouse MR, Beswick AD, Lenguerrand E, Blom AW. Influence of fixation methods on prosthetic joint infection following primary total knee replacement: meta-analysis of observational cohort and randomised intervention studies. J Clin Med Res 2019;8. Available from: http://dx.doi.org/https://doi.org/10.3390/jcm8060828.

69. Ding H, Yao J, Chang W, Liu F. Comparison of the efficacy of static versus articular spacers in two-stage revision surgery for the treatment of infection following total knee arthroplasty: a meta-analysis. J Orthop Surg Res. 2017; 12:151.

70. Voleti PB, Baldwin KD, Lee G-C. Use of static or articulating spacers for infection following total knee arthroplasty: a systematic literature review. J Bone Joint Surg Am. 2013;95:1594-9.

71. Kunutsor SK, Beswick AD, Whitehouse MR, Blom AW. One- and two-stage surgical revision of infected elbow prostheses following total joint replacement: a systematic review. BMC Musculoskelet Disord. 2019;20:467.

72. Kunutsor SK, Wylde V, Beswick AD, Whitehouse MR, Blom AW. One- and two-stage surgical revision of infected shoulder prostheses following arthroplasty surgery: a systematic review and meta-analysis. Sci Rep. 2019;9:232.

73. Kunutsor SK, Whitehouse MR, Blom AW, Board T, Kay P, Wroblewski BM, et al. One- and two-stage surgical revision of peri-prosthetic joint infection of the hip: a pooled individual participant data analysis of 44 cohort studies. Eur J Epidemiol. 2018;33:933-46.

74. Kunutsor SK, Whitehouse MR, Blom AW, Beswick AD, INFORM Team. Reinfection outcomes following one- and two-stage surgical revision of infected hip prosthesis: a systematic review and meta-analysis. PLoS One. 2015;10:e0139166
75. Kunutsor SK, Whitehouse MR, Lenguerrand E, Blom AW, Beswick AD, INFORM Team. Re-infection outcomes following one- and two-stage surgical revision of infected knee prosthesis: a systematic review and metaanalysis. PLoS One. 2016;11:e0151537.

\section{Publisher's Note}

Springer Nature remains neutral with regard to jurisdictional claims in published maps and institutional affiliations.
Ready to submit your research? Choose BMC and benefit from:

- fast, convenient online submission

- thorough peer review by experienced researchers in your field

- rapid publication on acceptance

- support for research data, including large and complex data types

- gold Open Access which fosters wider collaboration and increased citations

- maximum visibility for your research: over $100 \mathrm{M}$ website views per year

At $\mathrm{BMC}$, research is always in progress.

Learn more biomedcentral.com/submissions 